Check for updates

Cite this: RSC Adv., 2017, 7, 21655

\section{Functional group effect on flame retardancy, thermal, and mechanical properties of organophosphorus-based magnesium oxysulfate whiskers as a flame retardant in polypropylene $\uparrow$}

\begin{abstract}
Li Dang, ${ }^{\text {ac }}$ Xueying Nai, ${ }^{\text {b }}$ Yaping Dong ${ }^{\mathrm{b}}$ and Wu Li (D) *ab
In this paper, magnesium oxysulfate whiskers (MOSw) were reacted with dodecyl dihydrogen phosphate (DDP) to prepare DDP functionalized MOSw (DDPMOSw). The morphology and structure of DDPMOSw were characterized by scanning electron microscopy (SEM), transmission electron microscopy (TEM), Fourier transform infrared spectroscopy (FTIR), and X-ray photoelectron spectroscopy (XPS). Then MOSw and DDPMOSw were respectively incorporated into polypropylene (PP) to obtain hybrid composites via the melt mixing method. SEM results showed that the DDPMOSw were distributed more evenly within the PP matrix than MOSw, resulting in the improved thermal stability, nominal strain at break, and impact toughness of PP/DDPMOSw in comparison with PP/MOSw. The flammability of the composites was investigated using limiting oxygen index (LOI) and cone calorimetry (CC) tests. The results showed that the introduction of DDPMOSw into the PP matrix further increased the LOI, meanwhile, reducing the heat release rate (HRR), smoke production rate (SPR) and $\mathrm{CO}$ and $\mathrm{CO}_{2}$ release. SEM and energy dispersive spectroscopy (EDS) analyses of the char residues implied two reasons for the more efficient flame-retardant properties of PP/ DDPMOSw than PP/MOSw: (i) DDPMOSw was more thoroughly decomposed to release more nonflammable gases and absorb more heat during the combustion process (gas-phase flame-retardant effect); (ii) DDP induced the formation of the carbonaceous residue, leading to a compact and coherent char based on $\mathrm{MgO}$ whiskers backbone (condensed-phase flame-retardant effect). Besides, FTIR results indicated that the phosphorous compound layer in the condensed phase also acted as a protective shield.
\end{abstract}

Received 9th March 2017 Accepted 12th April 2017 DOI: 10.1039/c7ra02863f rsc.li/rsc-advances retardants. $^{6-8}$ Recently, some nanoparticles including the carbon materials (carbon microspheres, carbon nanotubes, carbon nanofibers, carbon black particles, expandable graphite, etc.), ${ }^{\mathbf{8 - 1 2}}$ layered silicate, ${ }^{\mathbf{1 3}}$ metal hydroxides (magnesium hydrogen, aluminium hydroxide, etc.), ${ }^{\mathbf{1 4 1 5}}$ and minerals (montmorillonite, sepiolite, kaolinite, huntite, hydromagnesite, nesquehonite, magnesium phosphate octahydrate, etc. $)^{\mathbf{1 6 - 1 9}}$ have drawn more attention to retard the combustion of polymer matrices. Thereinto, the metal hydroxides and minerals are greatly used as environmental friendly flame retardants, because of no production of halogenated compounds reducing toxicity and cost-effective price. However, in general, their flame retardant efficiency is lower than that of halogenated flame retardants, leading to a high mass loading. For example, a great amount up to $40-60 \%$ mass fraction of magnesium hydroxide $(\mathrm{MH})^{15}$ should be added to meet the conventional requirement of flame retardant grade. The high filler loading always leads to a deterioration of the mechanical performance in the composites, especially for the toughness of materials.

As a kind of typical inorganic whisker, magnesium oxysulfate whiskers (MOSw) have extremely high mechanical properties due to their small dimensions nearly without defects. With the
${ }^{a}$ Key Laboratory of Salt Lake Resources Chemistry, Qinghai Institute of Salt Lakes, Chinese Academy of Sciences, Xining 810008, China.E-mail: liwu2016@126.com

${ }^{b}$ Key Laboratory of Comprehensive and Highly Efficient Utilization of Salt Lake Resources, Qinghai Institute of Salt Lakes, Chinese Academy of Sciences, Xining 810008, China

'University of Chinese Academy of Sciences, Beijing 100049, China

$\dagger$ Electronic supplementary information (ESI) available. See DOI: 10.1039/c7ra02863f 
theoretical formula of $x \mathrm{MgSO}_{4} \cdot y \mathrm{Mg}(\mathrm{OH})_{2} \cdot z \mathrm{H}_{2} \mathrm{O}, \quad \mathrm{MOSw}$ decompose through an endothermic reaction to release a large amount of water vapor and oxysulfides, which effectively isolate the flame and dilute the flammable gases in the gas phase. Besides, MOSw also have high aspect ratio, low density and cost. $^{20,21}$ All these characteristics make the MOSw as an ideal candidate for polymers flame retardant. Actually, there were a few reports about MOSw application in polymers as a flame retardant. $\mathrm{Lu}$ et al. $^{22}$ prepared halogen-free flame retardant maleated polyethylene/MOSw composites with organomodified montmorillonite (OMMT), and found a synergistic flame retardant effects of MOSw and OMMT. Fang ${ }^{23}$ and Lu et $a .^{24}$ studied the flame retardant efficiency of MOSw for the silicone rubber (SR) and low density polyethylene (LDPE), respectively, with microencapsulated red phosphorus (MRP) as a synergist. The results showed that addition of MOSw indeed improved the flame retardancy of SR and LDPE, but sacrificed the mechanical properties, especially for the elongation at break. Beyond these, MOSw was also used in flame retardant acrylonitrile butadiene styrene (ABS) composites with zinc stearate addition. ${ }^{25}$ The authors figured that the better dispersion of MOSw could further improve the flame retardancy of the composites. Based on all these reports, it was found that the high MOSw loading deteriorated the mechanical performance in the composites like other metal hydroxide flame retardants. Two of the appropriate ways respectively are to use synergistic agents in order to reduce the amount of MOSw, and to improve the flame retardant efficiency of MOSw resulting from the better dispersion in the matrix.

Organophosphate is an important kind of organic phosphorus flame retardant (OPFR) which has been widely used in various polymers, like polycarbonate/ABS blend, poly(methyl methacrylate) (PMMA), polystyrene (PS), etc. ${ }^{26-29}$ Generally, the flame-retardant mechanisms of organophosphorus are inducing significant carbonaceous residue on the surface and forming a glassy layer in condensed phase acting as a protective barrier. On the other hand, organophosphate contains hydrophobic groups, such as long-chain alkyl, phenyl, and other derivatives, which may exhibit positive effects for declining aggregation and enhancing compatibility of inorganic fillers in polymers. Hence, it is expected that functionalized MOSw with organophosphate performs higher flame retardant efficiency than MOSw due to the synergistic effect and more dispersed state. Moreover, the loss of mechanical properties of composites should also be relieved with addition of functionalized MOSw.

In this work, a facile functionalization method has been used to prepare modified MOSw with dodecyl dihydrogen phosphate (DDP). And then PP composites filled with MOSw and DDP functionalized MOSw (DDPMOSw) were prepared by melt blending method. DDPMOSw was characterized by Fourier transform infrared spectroscopy (FTIR), X-ray photoelectron spectroscopy (XPS), scanning electron microscope (SEM) and transmission electron microscopy (TEM). And the flame retardancy of MOSw and DDPMOSw in PP matrix was estimated by limit oxygen index (LOI) and cone calorimeter (CC) tests. The char residues obtained after calcination were analyzed by SEM, energy dispersive spectrometry (EDS) and FTIR in order to discuss the flame-retardant mechanism. Furthermore, thermogravimetric analysis (TGA) was used to study the thermal decomposition behaviors of PP composites.

\section{Experimental}

\subsection{Materials}

Dodecyl dihydrogen phosphate (DDP) was purchased from Wako Pure Chemical Industries, Ltd. Potassium hydroxide (95.0\%) was purchased from Tianjin Kemiou Chemical Regent Co., Ltd. Isotactic polypropylene (PP, T30S) was purchased from Maoming Petrochemical Co., Ltd., Maoming, China. Antioxidant 1010 (95.0\%) was purchased from Tokyo Chemical Industry (TCI), Tokyo, Japan. MOSw $\left(\mathrm{MgSO}_{4} \cdot 5 \mathrm{Mg}(\mathrm{OH})_{2} \cdot 2 \mathrm{H}_{2} \mathrm{O}\right)$ with a diameter of $0.5-1 \mu \mathrm{m}$ and a length of $10-50 \mu \mathrm{m}$ was obtained from a procedure described as our previous work. ${ }^{30}$ All other materials were commercially available and used as received unless otherwise noted.

\subsection{Preparation of DDP functionalized MOSw}

A certain amount of DDP was dissolved in $10 \mathrm{~mL}$ potassium hydroxide aqueous solution after $3 \mathrm{~min}$ ultrasonic process. And then DDP solution was added into $150 \mathrm{~mL}$ pretreated MOSw slurry with mechanical stirring. After only 5 min reaction at room temperature with mechanical stirring, DDP functionalized MOSw was obtained. The product was filtered and washed with plenty of distilled water to remove excessive surfactant. The sample was collected and dried at $60{ }^{\circ} \mathrm{C}$ in an oven for $12 \mathrm{~h}$.

\subsection{Preparation of PP composites}

Before blending, all materials were dried at $70{ }^{\circ} \mathrm{C}$ for $8 \mathrm{~h}$ to eliminate the effect of moisture. And then the PP pellets, MOSw or DDPMOSw and antioxidant 1010 were mixed based on a certain percentage with an RM-200C torque rheometer (HAPRO, Harbin, China) at $190{ }^{\circ} \mathrm{C}$ with a rotor speed of $60 \mathrm{rpm}$ for $15 \mathrm{~min}$. Film samples with different thicknesses were obtained by compression molding with a $\mathrm{XH}-406 \mathrm{~B}$ press vulcanizer (Xihua, Dongguan, China) at $190{ }^{\circ} \mathrm{C}$ for $8 \mathrm{~min}$ without pressure and $7 \mathrm{~min}$ under a pressure of $15 \mathrm{MPa}$, subsequently. Then, the film samples were cooled to room temperature at the same pressure for $5 \mathrm{~min}$. All the samples were storied in a dry and room temperature $\left(23 \pm 2{ }^{\circ} \mathrm{C}\right)$.

\subsection{Characterization}

The chemical structures of MOSw and DDPMOSw were characterized by Fourier transform infrared (FTIR) and X-ray photoelectron spectroscopy (XPS). FTIR spectra were recorded on a Nexus infrared spectrometer (Thermo Nicolet. USA) with thin films on $\mathrm{KBr}$ at room temperature. Transition mode was used and the wave-number range was set from 4000 to 400 $\mathrm{cm}^{-1}$. XPS spectra were carried out using PHI-5702 multifunction electron spectrometer (American Physical Electronics) equipped with an $\mathrm{Al} \mathrm{K} \alpha \mathrm{X}$-ray source. Besides, the morphology and dispersion of MOSw and DDPMOSw were characterized by 
field emission scanning electron microscope (FESEM) and transmission electron microscope (TEM).

Tensile strength and modulus were measured at room temperature with CMT 6000 Electronic Universal Testing Machine according to ISO 527-2: 1993: using dumbbell-shaped specimens (1BB) with length of $30 \mathrm{~mm}$ and thickness of $2 \mathrm{~mm}$. The test speed was $10 \mathrm{~mm} \mathrm{~min}^{-1}$.

The morphology of MOSw and DDPMOSw was examined with a JSM-6701F field emission scanning electron microscope (FESEM) from JEOL using an acceleration voltage of $5.0 \mathrm{kV}$.

The surface morphology and microstructures of MOSw and DDPMOSw were observed by means of transmission electron microscopy (TEM, JEOL 2010).

FTIR spectra were obtained on a Nexus infrared spectrometer (Thermo Nicolet. USA) with thin films on $\mathrm{KBr}$ at room temperature. Transition mode was used and the wave-number range was set from 4000 to $400 \mathrm{~cm}^{-1}$.

X-ray photoelectron spectroscopy (XPS) measurement of MOSw and DDPMOSw was carried out using PHI-5702 multifunction electron spectrometer (American Physical Electronics) equipped with an $\mathrm{Al} \mathrm{K} \alpha \mathrm{X}$-ray source.

The composite samples were fractured in liquid nitrogen and the surfaces were observed after sputtering coated with gold with a JSM-6701F field emission scanning electron microscope (FESEM) from JEOL using an acceleration voltage of $5.0 \mathrm{kV}$.

Thermogravimetric analysis (TGA) was carried out (STA449F3 simultaneous thermal analyzer (German, Netzsch)) was used under $5{ }^{\circ} \mathrm{C} \min ^{-1}$ heating rate.

Limiting oxygen index (LOI) was carried out in an PX-01-005 oxygen index meter (Suzhou Phinix Quality Testing Instrument Co. Ltd., China) with sample measurement of $80 \times 10 \times 4 \mathrm{~mm}^{3}$, following the procedure described in the ASTM D2863 standard.

The cone were analyzed on a FTT cone calorimeter on the basis of standard ISO 5660-1. Sample size was $100 \times 100 \times 3.0$ $\mathrm{mm}^{3}$. All samples were wrapped by a layer of aluminum foil. They were then horizontally irradiated under a heat flux of 50 $\mathrm{kW} \mathrm{m} \mathrm{m}^{-2}$.

\section{Results and discussion}

\subsection{Characterization of functionalized magnesium oxysulfate whiskers}

FTIR spectra of MOSw, DDPMOSw and DDP are presented in Fig. 1. A strong characteristic band at $1118 \mathrm{~cm}^{-1}$ appears in MOSw spectrum, corresponding to the stretching vibration of $\mathrm{SO}_{4}{ }^{2-}$. The broad moderate band at $3423 \mathrm{~cm}^{-1}$ and the weak band at $1635 \mathrm{~cm}^{-1}$ are assigned to the stretching vibration of intermolecular hydrogen bonding and bending vibration of O-H groups, respectively. These two bands are also observed in the FTIR spectrum of DDP. Besides, other three characteristic bands appears: the broad band at $2377 \mathrm{~cm}^{-1}$ is assigned to the characteristic $\mathrm{P}-\mathrm{O}-\mathrm{H}$ adsorption, ${ }^{31}$ the weak band at $1238 \mathrm{~cm}^{-1}$ is assigned to the stretching vibration of $\mathrm{P}=\mathrm{O},{ }^{32}$ the strong band at $1029 \mathrm{~cm}^{-1}$ and weak bands at 984 and $891 \mathrm{~cm}^{-1}$ are all assigned to the stretching vibration of $\mathrm{P}-\mathrm{O}-\mathrm{C} .{ }^{33}$ Additionally, the sharp moderate band at $1469 \mathrm{~cm}^{-1}$ was assigned to the deformation vibration of $\mathrm{CH}_{2}$. As for DDPMOSw, firstly, the

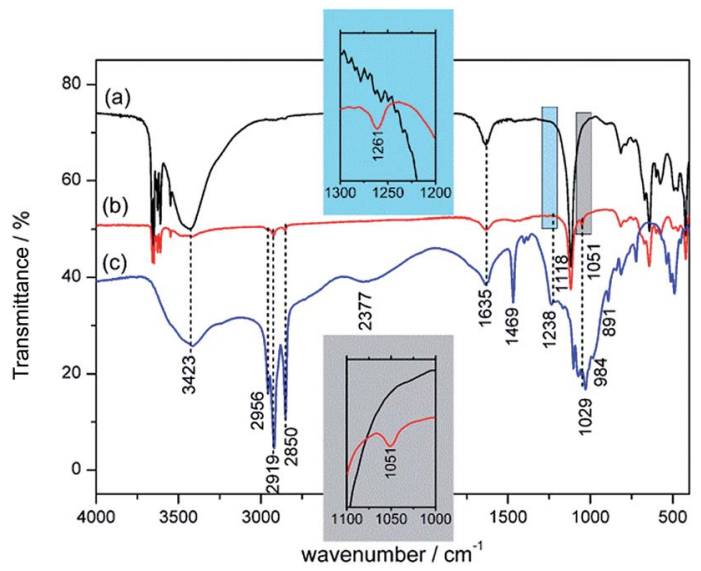

Fig. 1 FTIR spectra of (a) MOSw, (b) DDPMOSw and (c) DDP.

appearance of weak bands at 2956, 2919 and $2850 \mathrm{~cm}^{-1}$, corresponding to the asymmetrical and symmetrical stretching absorption bands for $\mathrm{CH}_{3} / \mathrm{CH}_{2}$, indicate that chemical or physical adsorbed DDP existed after modification. What's more, the intensity of all the absorption bands related to $\mathrm{O}-\mathrm{H}$ groups (about $3600 \mathrm{~cm}^{-1}$ region, $3423 \mathrm{~cm}^{-1}$ and $1635 \mathrm{~cm}^{-1}$ ) decrease significantly in comparison to both MOSw and DDP, even disappear the $\mathrm{P}-\mathrm{O}-\mathrm{H}$ adsorption band. Hence, it is supposed that DDP bonds on MOSw's surface with reaction between $\mathrm{P}-\mathrm{O}-\mathrm{H}$ and $\mathrm{O}-\mathrm{H}$ groups on the surface. Further, the two insets show that the adsorption bands for $\mathrm{P}=\mathrm{O}$ and $\mathrm{P}-\mathrm{O}-\mathrm{C}$ both shift up by $22-23 \mathrm{~cm}^{-1}$, indicating that $\mathrm{P}-\mathrm{O}-\mathrm{Mg}$ groups could be formed since the weaker electron-withdrawing capacity of $\mathrm{Mg}$. As reported by Zhuang et al., ${ }^{32}$ both $\mathrm{P}-\mathrm{O}-\mathrm{C}$ and $\mathrm{P}=\mathrm{O}$ bands of alkyl phosphate shifted up with the increasing of substituent alkyl groups since electron-donating capacity increasing. On the other way around, Mäkie et al. ${ }^{33}$ reported that a great downshift of $\mathrm{P}=\mathrm{O}$ band by $45-55 \mathrm{~cm}^{-1}$ was observed when trimethylphosphate was adsorbed to Fe oxides. They attributed this large downshift to the interactions with Fe Lewis acid sites to form $\mathrm{P}=\mathrm{O}-\mathrm{Fe}$ groups. However, in our case, $\mathrm{P}-\mathrm{O}-\mathrm{Mg}$ rather than $\mathrm{P}=$ $\mathrm{O}-\mathrm{Mg}$ should be formed since the lower electronegativity of $\mathrm{Mg}$ than $\mathrm{H}$ element.

In order to further investigate the composition of functionalized MOSw, XPS was used to analyze the varieties and states of different elements on the surface of DDPMOSw. Before the XPS analysis, the samples were ultrasonically cleaned in ethanol bath. In Fig. 2a, both MOSw and DDPMOSw show several main character peaks located at $984 \mathrm{eV}, 533 \mathrm{eV}, 285 \mathrm{eV}, 169 \mathrm{eV}, 89 \mathrm{eV}$ and $50 \mathrm{eV}$, which were assigned to O Auger, O1s, C1s, S2p, Mg2s and Mg2p signals, respectively. ${ }^{30}$ Phosphoric peak at $133.5 \mathrm{eV}$ appears at the position of DDPMOSw, while no phosphoric peak is detected for MOSw sample. It should be noted that the appearance of C1s signal in Fig. 2a is due to the surface contamination of organic chemicals during the transfer of MOSw to the vacuum chamber in a laboratory setting. The content of C element are listed in Table S1, $\dagger$ as well as the other elements. Obviously, the content of $\mathrm{P}$ element and $\mathrm{C}$ element increase from $0 \%$ and $28.08 \%$ to $1.97 \%$ and $41.23 \%$, respectively, after reaction with DDP. Nevertheless, the contents of $\mathrm{Mg}$, 

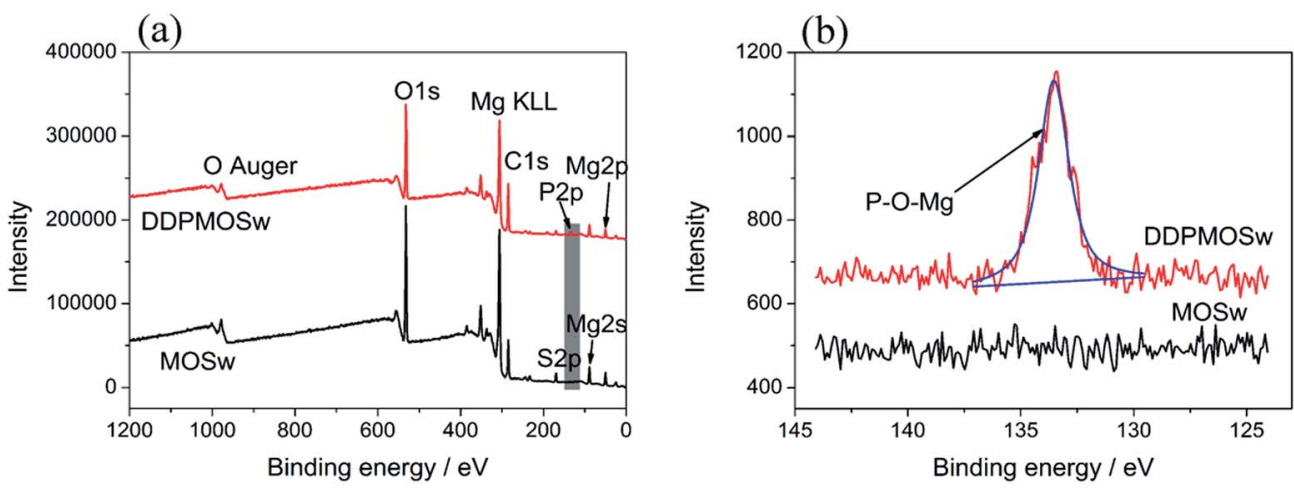

(c)
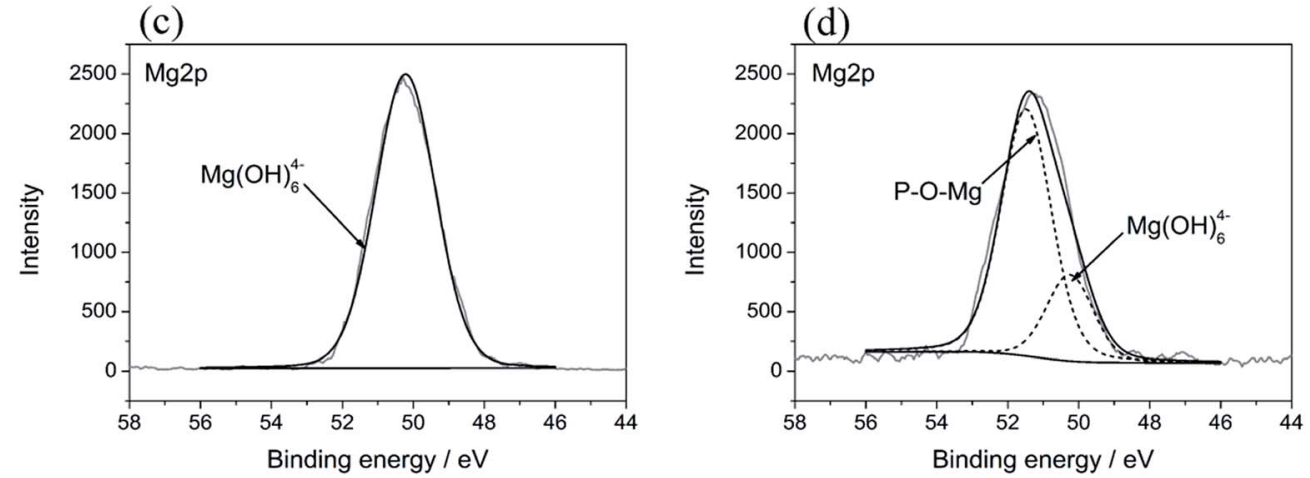

Fig. 2 XPS spectra of MOSw and DDPMOSw: (a) full-scan spectra, (b) high-resolution spectra of P2p peak, (c) high-resolution spectrum of Mg2p peak of MOSw, and (d) high-resolution spectrum of Mg2p peak of DDPMOSw.

$\mathrm{S}$ and $\mathrm{O}$ all decrease since there is no $\mathrm{Mg}$ or $\mathrm{S}$ element containing in DDP, and the content of $\mathrm{O}$ in DDP is lower than that of MOSw.

Moreover, curve-fitting analysis of high-resolution Mg2p spectra of MOSw and DDPMOSw samples are presented in Fig. 2c and d. It can be observed that an extra peak at $51.4 \mathrm{eV}$ appeared on DDPMOSw, apart from the binding energy of $\mathrm{Mg}(\mathrm{OH})_{6}{ }^{4-}$ at $50.3 \mathrm{eV}^{34}$ Therefore, it can be inferred that chemical bonds ( $\mathrm{P}-\mathrm{O}-\mathrm{Mg}$ ) are formed by the reaction of $\mathrm{P}-\mathrm{O}-\mathrm{H}$ and the $\mathrm{O}-\mathrm{H}$ groups on MOSw surface, ${ }^{35,36}$ referring to the FTIR results discussed before. All these variations indicated that DDP is well bound to the surface of MOSw after the facile modification.

Fig. 3 shows the SEM and TEM micrographs of MOSw and DDPMOSw. Tufted or sector aggregated whiskers are easily observed in Fig. 3a, owing to the high polarity of MOSw. By comparison, DDPMOSw shows much better dispersion than MOSw, as seen from Fig. 3b. The more observed single whiskers indicate that the agglomerates are effectively separated after modification. The surface morphology and microstructure of MOSw and DDPMOSw are further observed by means of TEM. Fig. 3c shows a straight and smooth edge of MOSw, while a thin coating layer about $\mathbf{1 0 - 1 5} \mathrm{nm}$ is coated on the surface of DDPMOSw, as shown in Fig. 3d. As such, functionalized MOSw shows much higher compatibility in organic phases or solvents. In order to compare the compatibility of MOSw and DDPMOSw, $\mathrm{H}_{2} \mathrm{O}$ and $n$-hexane were utilized to prepare suspensions of MOSw. The solutions have been ultrasonically treated for $5 \mathrm{~min}$. Fig. 4 shows pictures of the dispersion and compatibility state of MOSw and DDPMOSw suspensions after $5 \mathrm{~h}$ of standing. The dispersion of MOSw is stable in $\mathrm{H}_{2} \mathrm{O}$, resulting from the high polarity of MOSw and the good hydrogen bonding ability between $\mathrm{OH}^{-}$of MOSw and hydrogen in $\mathrm{H}_{2} \mathrm{O}$. However, MOSw is poorly dispersed in $n$-hexane with all samples sank on the bottom. In contrast, DDPMOSw generates a homogeneously suspension in $n$-hexane with a milk white solution but almost all floated on $\mathrm{H}_{2} \mathrm{O}$. Because the polarity of $n$-hexane is much lower than that of $\mathrm{H}_{2} \mathrm{O}$, the poorly polar DDPMOSw with alkyl chains on the surface can be preferentially dissolved in $n$ -
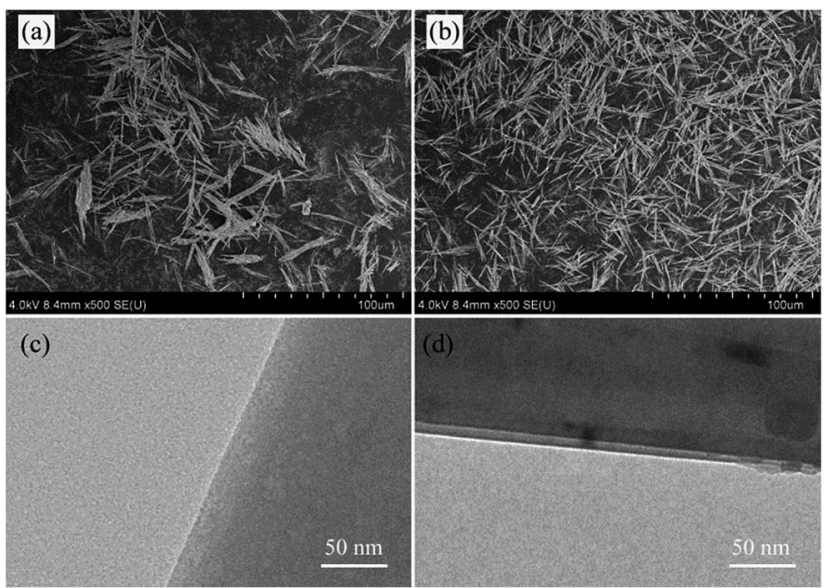

Fig. 3 SEM and TEM micrographs of MOSw ( $a$ and $c$ ) and DDPMOSw (b and $d)$. 


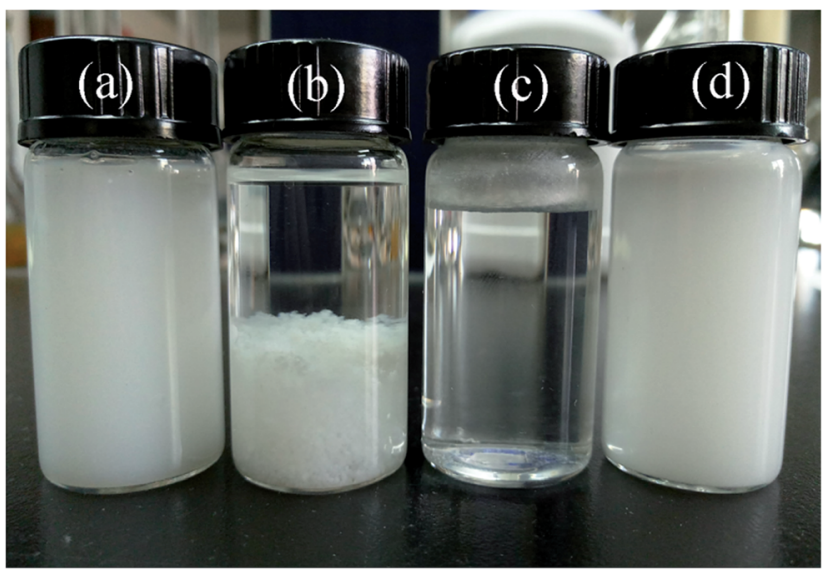

Fig. 4 Observation of functionalized MOSw dispersions in $\mathrm{H}_{2} \mathrm{O}$ and $n$ hexane after ultrasonication for 5 min and waiting for $5 \mathrm{~h}$ : (a) MOSw in $\mathrm{H}_{2} \mathrm{O}$; (b) MOSw in $n$-hexane; (c) DDPMOSw in $\mathrm{H}_{2} \mathrm{O}$; (d) DDPMOSw in $n$-hexane.

hexane. The water contact angle of MOSw and DDPMOSw samples were also measured, as shown in Fig. S2.†

\subsection{Morphological analysis of PP composites}

The fractured surfaces of PP composites were observed with SEM after sputtering coated with gold, as show in Fig. 5. A typical feature of composites prepared from MOSw is the big agglomerations and out-of-flatness surface, which means no interface interaction between MOSw and the PP molecular chains. By contrast, PP/DDPMOSw composite shows a finer distribution of whiskers in the PP matrix with a smooth and flat surface, which can be observed in Fig. $5 \mathrm{c}$ and $\mathrm{d}$. The uniform distribution is ascribed to two possible reasons: (i) the polarity of functionalized MOSw is greatly lower so that agglomerations decrease; (ii) the alkyl chains coated on DDPMOSw surface are better compatible with PP molecular chains. However, the higher-magnification SEM image of PP/DDPMOSw (Fig. S3†)
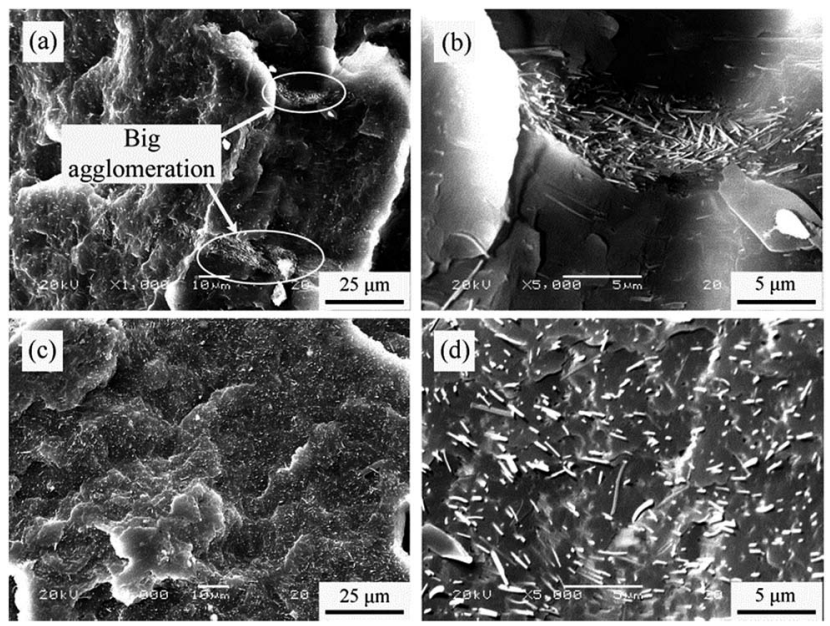

Fig. 5 SEM micrographs of cryo-fractured surface of PP/MOSW (a and b) and PP/DDPMOSw composites (c and d). shows a smooth surface of protruding whiskers smooth without wrapped melting. Hence, it is conclude that functionalized DDPMOSw could not completely eliminate the compatibility issues of MOSw and the PP matrix.

\subsection{Mechanical properties of PP composites}

Fig. 6 shows the typical tensile stress-strain curves of PP/MOSw and PP/DDPMOSw composites. Three important parameters including yield strength, Young's modulus, and nominal strain at break are summarized in Table 1. Obviously, both PP/MOSw and PP/DDPMOSw composites show lower yield strength than that of neat $\mathrm{PP}$, which is mainly due to the high filler content (30 $\mathrm{wt} \%$ ). However, the tensile modulus of $\mathrm{PP} / \mathrm{MOSw}$ and $\mathrm{PP} /$ DDPMOSw composites are much higher than that of neat PP attributing to the rigidity of MOSw themselves. In addition to these, the nominal strain at break is decreased in both composite samples, but much less for that containing the DDPMOSw. This is due to the finer dispersion of DDPMOSw in the PP matrix, as discussed above. ${ }^{8}$ Finally, Table 1 also shows the impact strength of neat PP and its composites. Incorporation of MOSw declines the impact strength of PP composite to $1.29 \mathrm{~kJ} \mathrm{~m}^{-2}$, mainly resulting from the the formation of microcracks around the MOSw, especially for the agglomerations. On the contrary, PP/DDPMOSw sample shows enhanced impact strength as to $3.06 \mathrm{~kJ} \mathrm{~m}^{-2}$ since the uniform distribution of whiskers.

\subsection{Thermal decomposition behaviours of PP composites}

Fig. 7 shows the TG and DTG curves of neat PP, PP/MOSw, and PP/DDPMOSw composites under nitrogen condition, and the corresponding data are listed in Table 2 . In case of neat PP, the thermal decomposition behavior exhibits a single stage with almost $100 \%$ weight loss at $700{ }^{\circ} \mathrm{C}$. When MOSw is added into the PP matrix, the $T_{05}$ and $T_{\text {peak }}$ values are increased from $313.5^{\circ} \mathrm{C}$ and $395.7{ }^{\circ} \mathrm{C}$ for neat PP to $388.6{ }^{\circ} \mathrm{C}$ and $457.6^{\circ} \mathrm{C}$ for $\mathrm{PP} / \mathrm{MOSw}$ composite, indicating significant improvement of thermal stability of PP. This improvement is more pronounced with addition of DDPMOSw into the PP matrix. Good dispersion of DDPMOSw in the PP matrix effectively retards the thermal

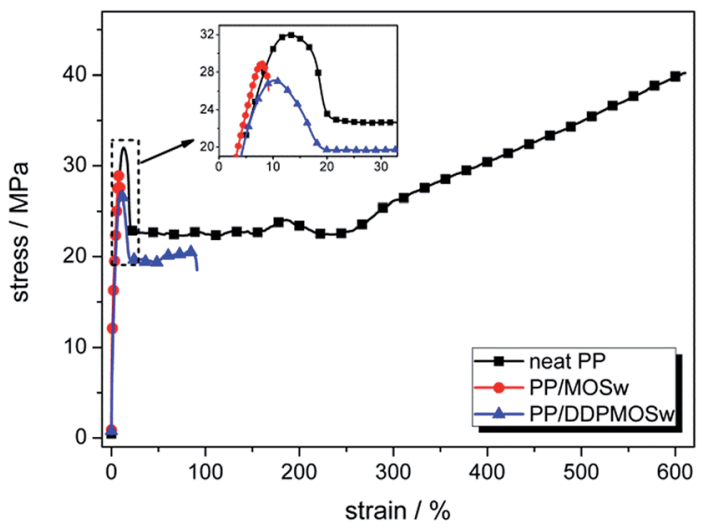

Fig. 6 Tensile stress-strain curves of neat PP, PP/MOSw, and PP/ DDPMOSw composites. 
Table 1 Mechanical properties of neat PP and its composites

\begin{tabular}{lllll}
\hline Sample & Yield strength $(\mathrm{MPa})$ & Young's modulus $(\mathrm{MPa})$ & Nominal strain at break $(\%)$ & ${\text { Impact strength }\left(\mathrm{kJ} \mathrm{m}{ }^{-2}\right)}$ \\
\hline Neat PP & $31.93 \pm 0.94$ & $597.71 \pm 61.82$ & $620.72 \pm 34.53$ & $1.71 \pm 0.07$ \\
PP/MOSw & $27.58 \pm 2.54$ & $969.82 \pm 42.63$ & $9.77 \pm 2.55$ & $1.29 \pm 0.13$ \\
PP/DDPMOSw & $27.13 \pm 1.68$ & $914.64 \pm 52.77$ & $91.13 \pm 13.01$ & $3.06 \pm 0.18$ \\
\hline
\end{tabular}

(a)

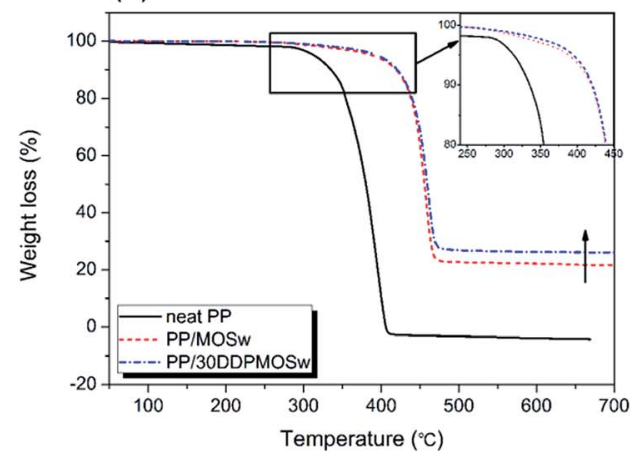

(b)

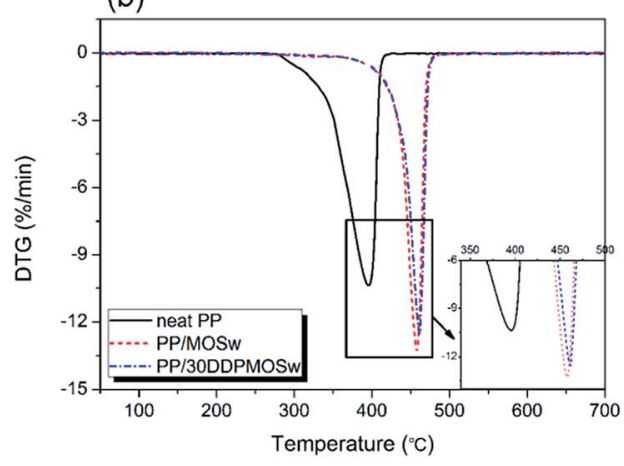

Fig. 7 Thermal decomposition curves of neat PP, PP/MOSw, and PP/DDPMOSw composites under nitrogen condition: TG (a) and DTG (b).

Table 2 Thermal decomposition data for each sample under nitrogen condition

\begin{tabular}{llll}
\hline Sample & $T_{05}\left({ }^{\circ} \mathrm{C}\right)$ & $T_{\text {peak }}\left({ }^{\circ} \mathrm{C}\right)$ & Residue $(\%)$ \\
\hline Neat PP & 313.5 & 395.7 & 0 \\
PP/MOSw & 388.6 & 457.6 & 21.7 \\
PP/DDPMOSw & 394.7 & 461.7 & 26.1 \\
\hline
\end{tabular}

motion of PP macromolecular chains, resulting in further enhancement in the thermal stability of PP/DDPMOSw. ${ }^{37-39}$ As shown in Fig. $\mathrm{S} 4, \dagger$ the thermal degradation behavior of MOSw exhibits three stage: (i) from $250{ }^{\circ} \mathrm{C}$ to $282^{\circ} \mathrm{C}$ lost about $8.4 \mathrm{wt} \%$, corresponding to the release of two crystal water molecules of $5 \mathrm{Mg}(\mathrm{OH})_{2} \cdot \mathrm{MgSO}_{4} \cdot 2 \mathrm{H}_{2} \mathrm{O}$; (ii) from $371{ }^{\circ} \mathrm{C}$ to $411{ }^{\circ} \mathrm{C}$ lost about $19.4 \mathrm{wt} \%$, due to the dehydration of $5 \mathrm{Mg}(\mathrm{OH})_{2} \cdot \mathrm{MgSO}_{4}$; (iii) from $848{ }^{\circ} \mathrm{C}$ to $888{ }^{\circ} \mathrm{C}$ lost about $18.01 \%$, attributed to the desulfation $\left(\mathrm{SO}_{3}\right)$ of $5 \mathrm{MgO} \cdot \mathrm{MgSO}_{4}$. Hence, only the former two steps dominate the decomposition of PP composites at $700{ }^{\circ} \mathrm{C}$. The calculated residual content of $\mathrm{PP} / \mathrm{MOSw}$ is $21.5 \mathrm{wt} \%$, which is quite close to the experimental result, $21.7 \%$, as shown in Table 2. This indicates that the incorporated MOSw do not promote the char residues formation of PP matrix. Only the released water vapor of MOSw isolates the flame and dilutes the flammable gases in the gas phase. Moreover, incorporation of DDPMOSw leads to an effective promotion of residual char content, which is $26.1 \%$ shown in Table 2 .

\subsection{Flame-retardant properties of PP composites}

The cone calorimeter based on oxygen consumption principle has been a universal method used to study the flammability characteristics of materials. It can be used to predict the combustion behavior of materials in a real fire so that remains one of the most useful bench-scale tests. ${ }^{37-42}$ The heat release rate (HRR) is a very important parameter as it expresses the intensity of a fire. Specifically, the peak of HRR (PHRR) is often used to describe the fire hazard behavior for actual situation. ${ }^{\mathbf{8 , 4 0 , 4 1}}$ Fig. 8a exhibits the HRR profiles of neat PP and its composites under a heat flux of $50 \mathrm{~kW} \mathrm{~m}{ }^{-2}$, and the related data are listed in Table 3. Neat PP is ignited in $52 \mathrm{~s}$ and shows a very sharp HRR curve at the time range of 50-350 s with a maximum of $915.7 \mathrm{~kW}$ $\mathrm{m}^{-2}$ at $165 \mathrm{~s}$. In comparison, the HRR curves of PP/MOSw and PP/ DDPMOSw both become flatter, indicating the gradual burning of the specimen through the thickness after the initial charred layers are formed. The peak HRR (PHRR) values decrease to 259.1 $\mathrm{kW} \mathrm{m} \mathrm{m}^{-2}$ and $243.3 \mathrm{~kW} \mathrm{~m}^{-2}$ for PP/MOSw and PP/DDPMOSw, respectively. Strangely enough as seen in Fig. 8a the time to PHRR shortens to $100 \mathrm{~s}$ and $105 \mathrm{~s}$ with addition of MOSw and DDPMOSw, respectively. Although the process of MOSw decomposition is endothermic, the thermal decomposition temperatures are also much higher than that of PP matrix $\left(350-400{ }^{\circ} \mathrm{C}\right)$, especially for the latter two stages. Therefore, MOSw and DDPMOSw retard the combustion of PP matrix mainly in the high temperature stage. Moreover, the whole combustion process is prolonged from $520 \mathrm{~s}$ for neat PP to $890 \mathrm{~s}$ and $920 \mathrm{~s}$ for PP/MOSw and PP/DDPMOSw, respectively. Fig. $8 \mathrm{~b}$ also presents the total HRR (THR) for all of the samples. The slope of the THR curve is assumed to be representative of fire spread. ${ }^{38,42,43}$ Obviously, THR is decreased with the addition of MOSw or DDPMOSw. The lowest THR value is observed for PP/DDPMOSw (72.8 MJ m${ }^{-2}$ ), which is decreased by $35.3 \%$ in contrast to virgin PP.

Smoke performance of flame-retardant material is a very important parameter in fire safety judgment since usually lots of smoke and toxic gases released during the combustion 

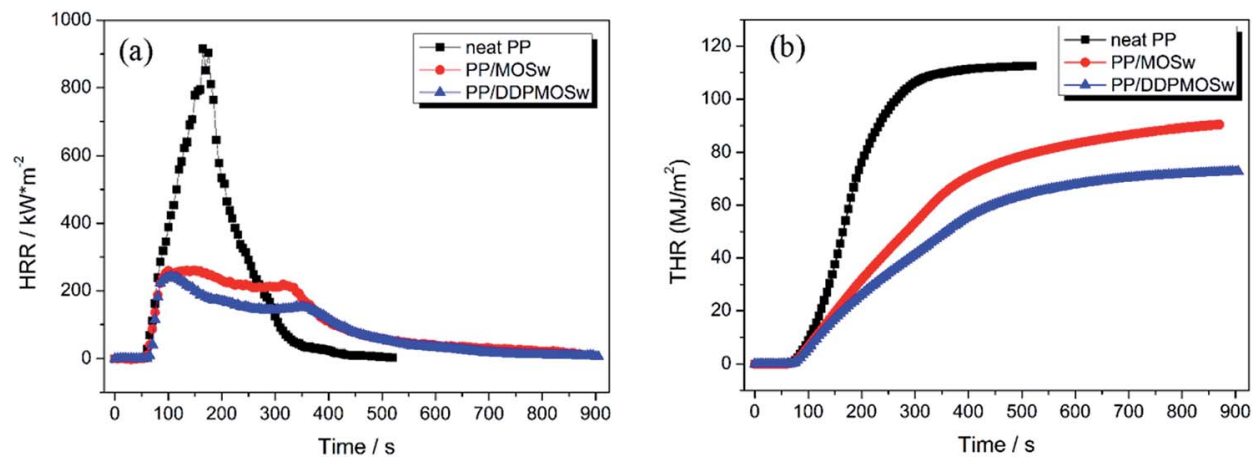

Fig. 8 HRR (a) and THR (b) curves of neat PP, PP/MOSw, and PP/DDPMOSw in cone calorimeter testing.

Table $3 \mathrm{LOI}$ and cone calorimeter data for each sample at $50 \mathrm{~kW} \mathrm{~m} \mathrm{~m}^{2 a}$

\begin{tabular}{|c|c|c|c|c|c|c|c|c|c|}
\hline Sample & LOI (\%) & TTI (s) & $\begin{array}{l}\text { PHRR } \\
\left(\mathrm{kW} \mathrm{m}^{-2}\right)\end{array}$ & $\begin{array}{l}\text { THR (MJ } \\
\mathrm{m}^{-2} \text { ) }\end{array}$ & $\begin{array}{l}\text { PSPR } \\
\left(\mathrm{m}^{2} \mathrm{~s}^{-1}\right)\end{array}$ & $\begin{array}{l}\text { TSP } \\
\left(\mathrm{m}^{2} \mathrm{~kg}^{-1}\right)\end{array}$ & $\begin{array}{l}\text { PCOP } \\
\left(\mathrm{g} \mathrm{s}^{-1}\right)\end{array}$ & $\begin{array}{l}\mathrm{PCO}_{2} \mathrm{P} \\
\left(\mathrm{g} \mathrm{s}^{-1}\right)\end{array}$ & $\begin{array}{l}\text { Residue } \\
\text { (wt } \% \text { ) }\end{array}$ \\
\hline Neat PP & 18.0 & 52 & 915.7 & 112.5 & 0.405 & 83.3 & 0.00798 & 0.529 & 0.83 \\
\hline PP/DDPMOSw & 26.1 & 64 & 243.3 & 72.8 & 0.078 & 36.2 & 0.00207 & 0.123 & 27.15 \\
\hline
\end{tabular}

${ }^{a}$ TTI, time to ignition; PHRR, peak heat release rate; THR, total heat release; PSPR, peak smoke production rate; TSP, total smoke production; $\mathrm{PCOP}$, peak $\mathrm{CO}$ production; $\mathrm{PCO}_{2} \mathrm{P}$, peak $\mathrm{CO}_{2}$ production.

process. ${ }^{42,43}$ Fig. 9 shows the smoke production rate (SPR) and total SPR (TSP) profiles of neat PP and its composites, and the related data are listed in Table 3. Neat PP exhibits a sharp SPR curve with the highest peak SPR (PSPR) value of $0.405 \mathrm{~m}^{2} \mathrm{~s}^{-1}$. Incorporation of MOSw and DDPMOSw to PP matrix dramatically flatten the SPR curves with peak values of 0.112 and 0.078 $\mathrm{m}^{2} \mathrm{~s}^{-1}$, respectively. TSP is reduced after introduction of either of the two whiskers, as shown in Fig. 9b. The lowest TSP value is observed for PP/DDPMOSw as $36.2 \mathrm{~m}^{2} \mathrm{~kg}^{-1}$, which is decreased by $56.5 \%$ in contrast to neat PP. The results indicate that introduction of DDPMOSw effectively suppressed the smoke emission during the combustion process of PP composites.

In general, $\mathrm{CO}$ and $\mathrm{CO}_{2}$ are the main types of the toxic gases produced from burning polymers since the asphyxiant properties causing fatality in a real fire situation. ${ }^{\mathbf{8} 43}$ Fig. 10 shows the variation of $\mathrm{CO}$ and $\mathrm{CO}_{2}$ productions in combustion process, and the corresponding parameters are also listed in Table 3. Both $\mathrm{CO}$ and $\mathrm{CO}_{2}$ production curves are similar to the HRR curves. With addition of MOSw, the peak CO production (PCOP) and peak $\mathrm{CO}_{2}$ production $\left(\mathrm{PCO}_{2} \mathrm{P}\right)$ are decreased from $0.00798 \mathrm{~g}$ $\mathrm{s}^{-1}$ and $0.529 \mathrm{~g} \mathrm{~s}^{-1}$ for neat PP to $0.00236 \mathrm{~g} \mathrm{~s}^{-1}$ and $0.133 \mathrm{~g} \mathrm{~s}^{-1}$, respectively. Much lower PCOP and $\mathrm{PCO}_{2} \mathrm{P}$ values are observed for the PP/DDPMOSw composite. Hence, DDPMOSw shows greatly suppression of $\mathrm{CO}$ and $\mathrm{CO}_{2}$ release, which may be favorable to fire rescue. Besides, Table 3 also presents that LOI increases from $18.0 \%$ for neat PP to $24.7 \%$ and $26.1 \%$ for PP/ MOSw and PP/DDPMOSw, respectively.

To reveal further the flame-retardant mechanism of MOSw and DDPMOSw, the morphologies and compositions of $\mathrm{PP} /$ MOSw and PP/DDPMOSw composites char residues after
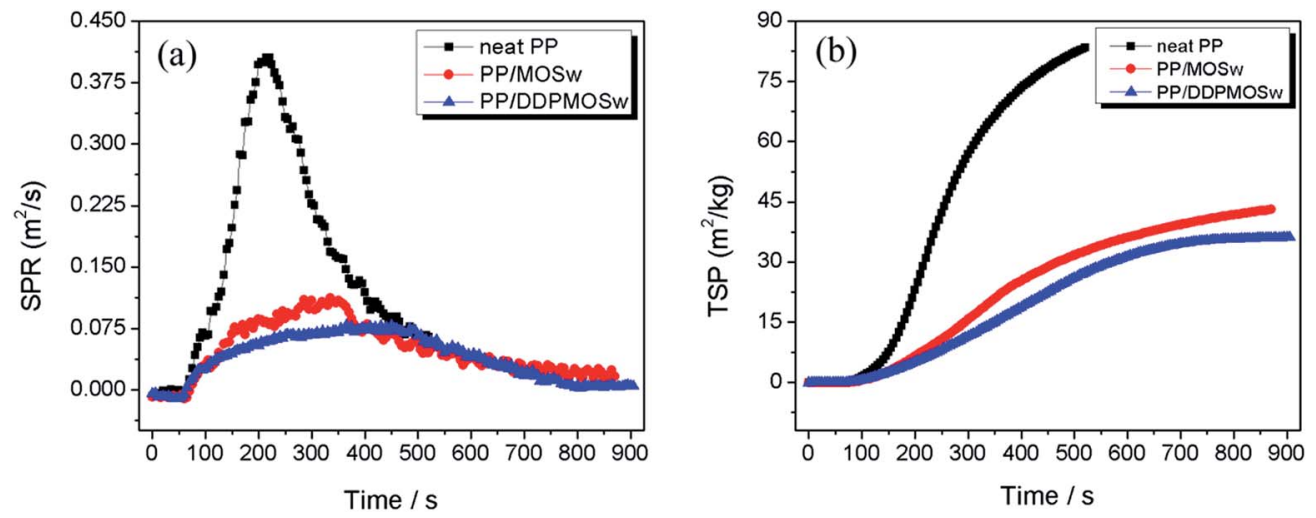

Fig. 9 SPR (a) and TSP (b) curves of neat PP, PP/MOSw, and PP/DDPMOSw in cone calorimeter testing. 

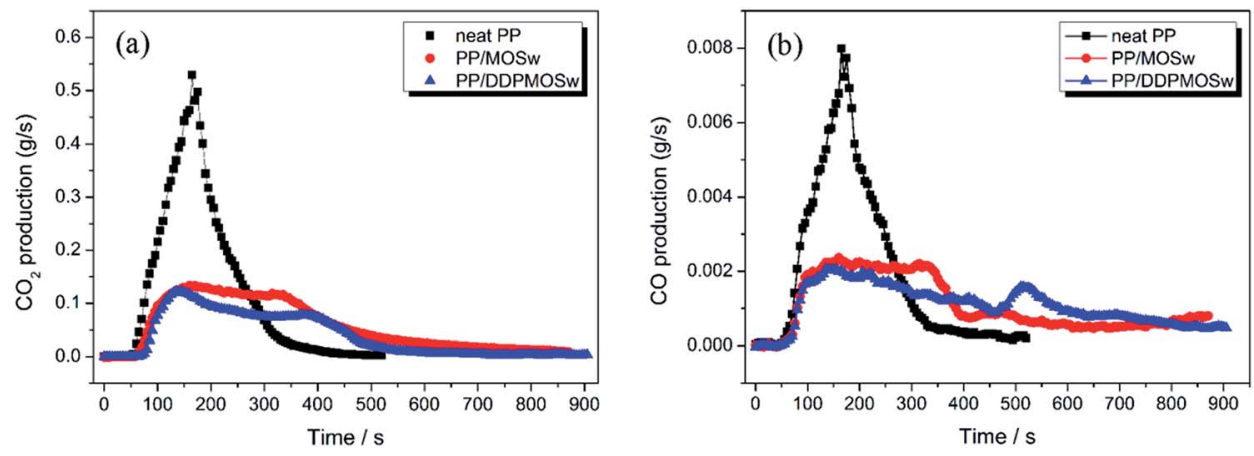

Fig. $10 \mathrm{CO}_{2}(\mathrm{a})$ and $\mathrm{CO}(\mathrm{b})$ production as a function of burning time for neat PP, PP/MOSW, and PP/DDPMOSw in cone calorimeter testing.

calcination were analyzed by SEM and EDS spectra, respectively, ${ }^{43}$ as shown in Fig. 11. For PP/MOSw sample, the char residue is gray and held a loose structure with holes that light mechanical stress (a finger touch was enough) caused the structure to crumble to dust. ${ }^{42}$ Fig. 10a shows that only whisker appearance is observed in the $\mathrm{PP} / \mathrm{MOSw}$ char. The whiskers are just physically piled together without adhesion since the PP matrix was almost fully burned. This kind of discontinuous and incompact char layer is not effective to prevent the burning extending into the inside of sample, although a lot of water is released during the endothermic decomposing of MOSw. Hence, the improved flame retardancy of $\mathrm{PP} / \mathrm{MOSw}$ is dominated by gas-phase flame-retarded effect of MOSw. The similar phenomenon has also been observed by other scholars. ${ }^{43}$ Conversely, the char residue of PP/DDPMOSw sample is more compact and solid than that of PP/MOSw composite, as shown in Fig. 10b. The whiskers are randomly oriented and entangled

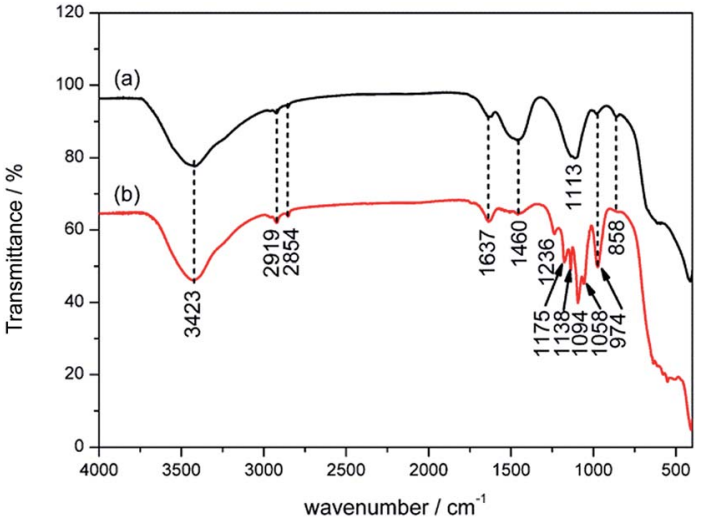

Fig. 12 FTIR spectra of the residual chars of PP/MOSW (a) and PP/ DDPMOSW (b) composites after calcination.
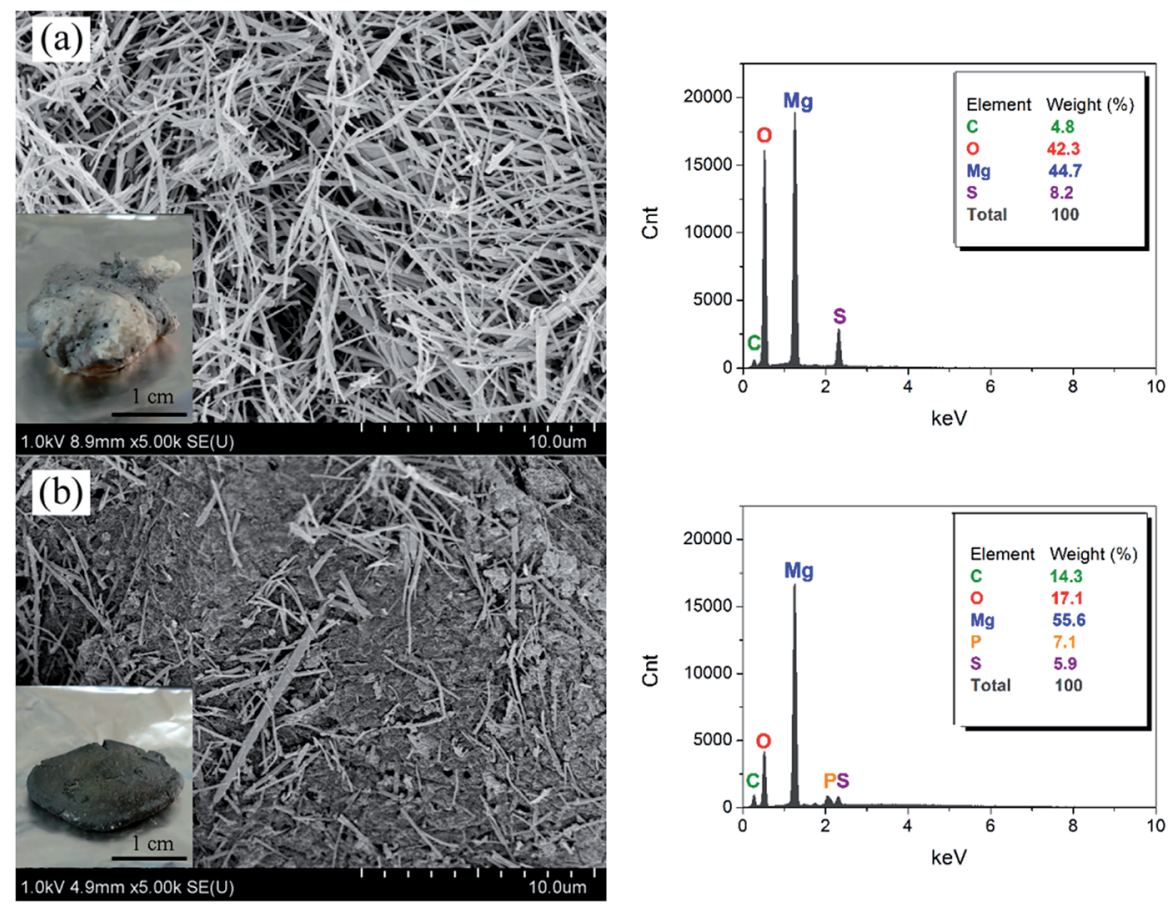

Fig. 11 SEM micrographs of the char residues of PP/MOSw (a) and PP/DDPMOSw (b) composites after calcination at $400{ }^{\circ} \mathrm{C}$ and their EDS spectra. 


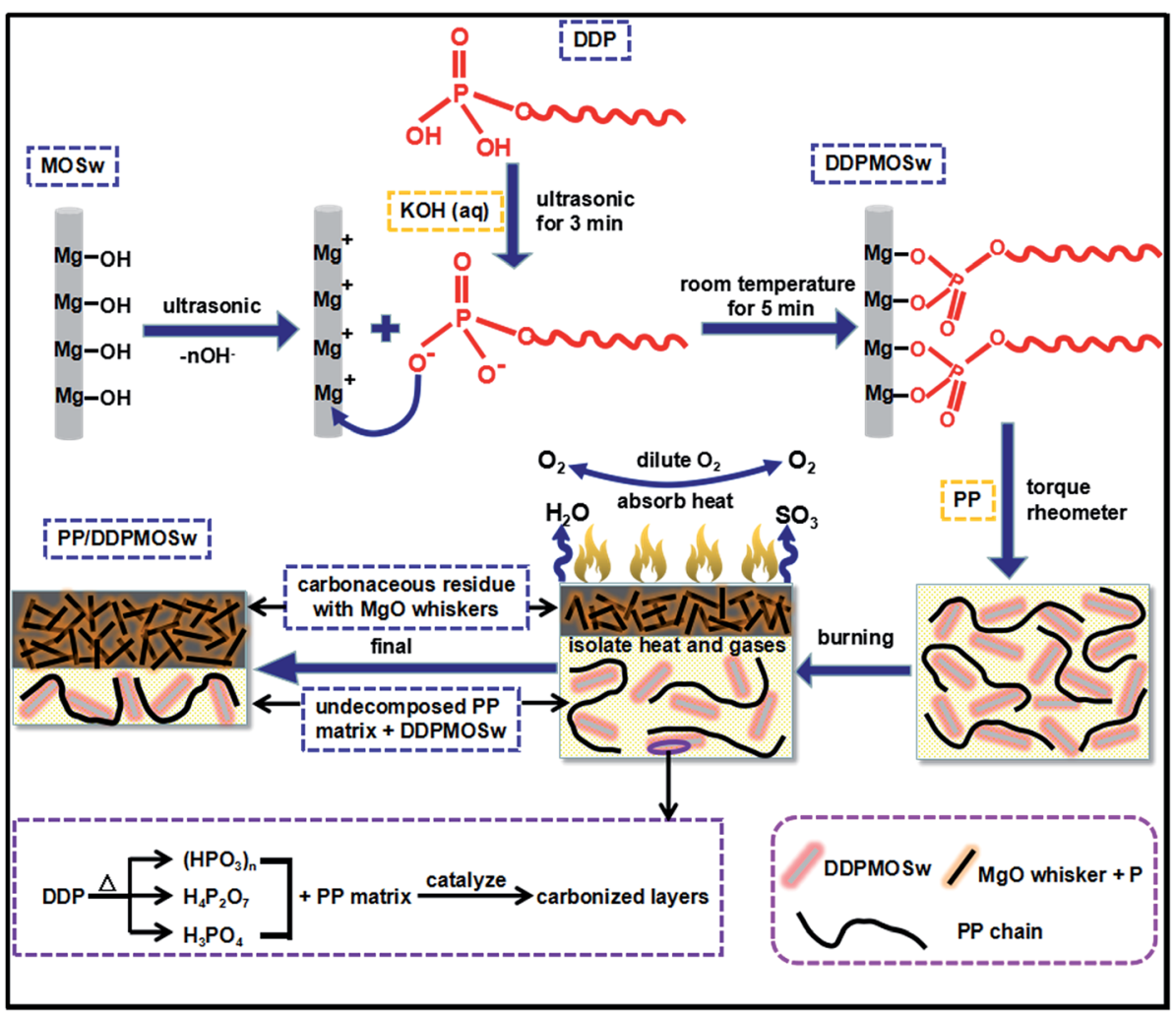

Scheme 1 Schematic illustration of the mechanism for the functionalized DDPMOSw and the enhanced flame resistance of the PP/DDPMOSw composite.

in the char residue to form a physical protective barrier. ${ }^{40}$ It is well known that organophosphorus flame retardants (OFRs) can induce the significant carbonaceous residue on polymers surface due to the catalysis of dehydrated phosphoric acid, metaphosphoric acid, pyrophosphoric acid, etc. Therefore, such a compact carbonaceous char is more effective to insulate the migration of heat and retard the flammable gases from feeding the flame, and it is also responsible for the lowest HRR peak (Fig. 8a).

From the EDS spectra, it is confirmed that partial MOSw decomposed to $\mathrm{MgO}$ whiskers after combustion, because of the higher $\mathrm{Mg} / \mathrm{S}$ ratio for both PP/MOSw (5.5/1) and PP/DDPMOSw (9.4/1) residues than MOSw (4.5/1). DDPMOSw is more thoroughly decomposed than MOSw so that more heat is absorbed and more nonflammable gases are released. In addition, $\mathrm{P}$ element is detected in the PP/DDPMOSw char, indicating that phosphoric compounds remained after combustion. FTIR was employed to further investigating the phosphoric compounds of PP/DDPMOSw char, as well as $\mathrm{PP} / \mathrm{MOSw}$ composite. As shown in Fig. 12, firstly, the bands at 1138 and $1059 \mathrm{~cm}^{-1}$ are assigned to the stretching vibration of $\mathrm{P}-\mathrm{O}-\mathrm{C}$ and $\mathrm{PO}_{2} / \mathrm{PO}_{3}$ structures in phosphate-carbon complexes, respectively. ${ }^{33}$ Secondly, the appearance of $\mathrm{P}-\mathrm{O}-\mathrm{P}$ stretching vibration band at 1175 and $1094 \mathrm{~cm}^{-1}$ implied the formation of $\mathrm{P}_{2} \mathrm{O}_{5}$ or $\mathrm{P}_{4} \mathrm{O}_{10}$ structures. ${ }^{44,45}$ Besides, the absorption band at $1236 \mathrm{~cm}^{-1}$ was corresponded to $\mathrm{P}=\mathrm{O}^{32}$ It is therefore believed that a polyphosphate protective layer formed in the char results in the more efficient flame-retardant properties.
On the basis of the above analysis, idealized mechanisms for DDP functionalized MOSw and the flame resistance of the PP/ DDPMOSw composite are illustrated in Scheme 1. MOSw is functionalized with DDP via a facial method, for the purpose of enhancing compatibility and flame-retardant properties of MOSw in the PP matrix. The DDP molecules are covalent bonded on the surface of MOSw with hydrophobic alkyl chain outwards. Therefore, DDPMOSw are highly compatible in the PP matrix. Compared with PP/MOSw, whose flame-retardant mechanism is presents in Scheme $\mathrm{S} 1, \dagger$ the more efficient flame-retardant properties of PP/DDPMOSw is mainly resulted from two reasons: (i) gas-phase flame-retarded effect of MOSw is further developed with more through decomposition process of DDPMOSw during combustion; (ii) condensed-phase flame retarded effect of DDP induces the formation of carbonaceous residue, and then a more compact and rigidity protective layer is created. Besides, the decomposition products of DDP including phosphoric acid, polyphosphoric acid, metaphosphoric acid, etc. also act as a barrier to prevented the migration of heat and the gases.

\section{Conclusions}

In this paper, magnesium oxysulfate whiskers (MOSw) were functionalized by dodecyl dihydrogen phosphate (DDP) via a facial method, in order to enhance the compatibility and flame-retardant properties in the PP matrix. Structure characterizations reveal that DDP molecules are covalent bonded with 
MOSw, forming a hydrophobic coating layer about 10-15 nm thickness on the surface of whiskers. Functionalization with DDP induces the improved MOSw dispersion in the PP matrix; thus the final flame-retardant PP composites exhibits enhanced nominal strain at break and impact toughness than those of PP/ MOSw, as well as the thermal stability. On the other hand, DDP functionalization intensifies the decomposition of MOSw more thoroughly, leading to release more nonflammable gases and absorb more heat during the combustion process. Besides, DDP also induces the formation of carbonaceous residue, leading to a more compact and coherent char based on $\mathrm{MgO}$ whiskers backbone. FTIR analyses of the char residues indicate that a layer of phosphorous compounds in the condensed phase also acts as a protective shield. Therefore, enhanced limit oxygen index (LOI) and the drastically reduced heat release rate (HRR), smoke production rate (SPR) and $\mathrm{CO}$ and $\mathrm{CO}_{2}$ releasing rate are achieved. This novel flame retardant system paves a new solution for decreasing the deterioration of the mechanical performance and enhancing the flame-retardant properties simultaneously, especially for the systems containing metal hydroxides as flame retarders.

\section{Conflict of interest}

The authors declare no competing financial interest.

\section{Acknowledgements}

We gratefully acknowledge projects from the "135" Foundation of the Qinghai Institute of Salt Lakes of the Chinese Academy of Sciences (Y460321111) and the National Natural Science Foundation of China (U1607101).

\section{References}

1 S. Iwamoto, S. Yamamoto, S. Lee and T. Endo, Composites, Part A, 2014, 59, 26-29.

2 A. Patti, R. Barretta, F. Marotti de Sciarra, G. Mensitieri, C. Menna and P. Russo, Compos. Struct., 2015, 131, 282-289.

3 D. Bagheriasl, P. Carreau, C. Dubois and B. Riedl, Compos. Sci. Technol., 2015, 117, 357-363.

4 W. Zuiderduin, C. Westzaan, J. Huetink and R. Gaymans, Polymer, 2003, 44, 261-275.

5 Q. X. Zhang, Z. Z. Yu, X. L. Xie and Y. W. Mai, Polymer, 2004, 45, 5985-5994.

6 L. Costes, F. Laoutid, M. Aguedo, A. Richel, S. Brohez, C. Delvosalle and P. Dubois, Eur. Polym. J., 2016, 84, 652-667.

7 Y. S. Gao, Q. Wang, J. Y. Wang, L. Huang, X. R. Yan, X. Zhang, Q. L. He, Z. P. Xing and Z. H. Guo, ACS Appl. Mater. Interfaces, 2014, 7, 5094-5104.

8 W. Y. Xing, W. Yang, W. J. Yang, Q. H. Hu, J. Y. Si, H. D. Lu, B. H. Yang, L. Song, Y. Hu and R. K. K. Yuen, ACS Appl. Mater. Interfaces, 2016, 39, 26266-26274.

9 Y. R. Yang, M. Niu, J. J. Li, B. X. Xue and J. M. Dai, Polym. Degrad. Stab., 2016, 134, 1-9.

10 E. Kuzdzał, B. Cichy, E. Kicko-Walczak and G. Rymarz, J. Appl. Polym. Sci., 2017, 134, 44371.
11 Z. Li and B. Qu, Polym. Degrad. Stab., 2003, 81, 401-408.

12 N. A. Isitman and C. Kaynak, Polym. Degrad. Stab., 2010, 95, 1523-1532.

13 A. B. Morgan, Polym. Adv. Technol., 2006, 17, 206-217.

14 L. C. Wang, G. L. Wang and P. K. Jiang, J. Appl. Polym. Sci., 2011, 120, 368-378.

15 N. H. Huang, eXPRESS Polym. Lett., 2010, 4, 227-233.

16 M. Hassan, M. Nour, Y. Abdelmonem, G. Makhlouf and A. Abdelkhalik, Polym. Degrad. Stab., 2016, 133, 8-15.

17 L. A. Hollingbery and T. R. Hull, Polym. Degrad. Stab., 2010, 95, 2213-2225.

18 L. C. Du, B. J. Qu and Z. J. Xu, Polym. Degrad. Stab., 2006, 91, 995-1001.

19 W. F. Tang, S. Zhang, X. Y. Gu, J. Sun, X. D. Jin and H. F. Li, Appl. Clay Sci., 2016, 132-133, 579-588.

20 T. Runčevski, C. Wu, H. Yu, B. Yang and R. Dinnebier, J. Am. Ceram. Soc., 2013, 96, 3609-3616.

21 X. Yan, D. Xu and D. Xue, Acta Mater., 2007, 55, 5747-5757.

22 H. Lu, Y. Hu, J. Xiao and Z. Wang, J. Mater. Sci., 2006, 41, 363-367.

23 S. L. Fang, Y. Hu, L. Song, J. Zhang and Q. He, J. Mater. Sci., 2008, 43, 1057-1062.

24 H. Lu, Y. Hu, L. Yang, Z. Wang, Z. Chen and W. Fan, Macromol. Mater. Eng., 2004, 289, 984-989.

25 B. Liu, Y. Zhang, C. Wan, Y. Zhang, R. Li and G. Liu, Polym. Bull., 2007, 58, 747-755.

26 N. F. Attia, E. S. Goda, M. A. Nour, M. W. Sabaa and M. A. Hassan, Mater. Chem. Phys., 2015, 168, 147-158.

27 Y. Shi and G. Wang, Appl. Surf. Sci., 2016, 385, 453-463.

28 Y. Wei, Y. Li, J. Duan and C. Jing, J. Hazard. Mater., 2014, 273, 53-60.

29 D. Price, L. Cunliffe, K. Bullett, T. Hull, G. Milnes, J. Ebdon, B. Hunt and P. Joseph, Polym. Degrad. Stab., 2007, 92, 1101-1114.

30 L. Dang, X. Y. Nai, D. H. Zhu, Y. W. Jing, X. Liu, Y. P. Dong and W. Li, Appl. Surf. Sci., 2014, 417, 325-331.

31 P. Zhang, S. Tian, H. Fan, Y. Chen and J. Yan, Prog. Org. Coat., 2015, 89, 170-180.

32 Y. Zhuang, Y. Wang, G. Zhao and G. Zhang, Spectrosc. Spectral Anal., 2010, 30, 157-158.

33 P. Mäkie, G. Westin, P. Persson and L. Osterlund, J. Phys. Chem. A, 2001, 115, 8948-8959.

34 D. H. Zhu, X. Y. Nai, S. J. Lan, S. J. Bian, X. Liu and W. Li, Appl. Surf. Sci., 2016, 390, 25-30.

35 F. Xie, F. Wu, G. Liu, Y. Mu, C. F. H. Wang and J. P. Giesy, Environ. Sci. Technol., 2014, 48, 582-590.

36 W. Zhang, B. Tian, K. Du, H. Zhang and F. Wang, Int. J. Electrochem. Sci., 2011, 6, 5228-5548.

37 G. Y. You, Z. Q. Cheng, Y. Y. Tang and H. W. He, Ind. Eng. Chem. Res., 2015, 54, 7309-7319.

38 W. Yang, Z. H. Jiang, J. Yang, B. H. Yang and H. D. Lu, Ind. Eng. Chem. Res., 2015, 54, 11048-11055.

39 H. Oyama, M. Sekikawa and S. Shida, Polym. Degrad. Stab., 2012, 97, 755-765.

40 H. F. Pan, W. Wang, Y. Pan, L. Song, Y. Hu and K. M. Liew, ACS Appl. Mater. Interfaces, 2015, 7, 101-111. 
$41 \mathrm{H}$. B. Chen, P. Shen, M. J. Chen, H. B. Zhao and D. A. Schiraldi, ACS Appl. Mater. Interfaces, 2016, 8, 3255732564.

42 X. S. Wang, H. C. Pang, W. D. Chen, Y. Lin, L. S. Zong and G. L. Ning, ACS Appl. Mater. Interfaces, 2014, 6, 7223-7235.
43 K. Lu, X. J. Cao, Q. S. Liang, H. T. Wang, X. W. Cui and Y. J. Li, Ind. Eng. Chem. Res., 2014, 53, 8784-8792.

44 J. N. Gavgani, H. Adelnia and M. M. Gudarzi, J. Mater. Sci., 2014, 49, 243-254.

45 X. Cheng, S. Liu and W. Shi, Prog. Org. Coat., 2009, 65, 1-9. 